Article

\title{
e-Purchase Intention of Taiwanese Consumers: Sustainable Mediation of Perceived Usefulness and Perceived Ease of Use
}

\author{
Massoud Moslehpour ${ }^{1}$ (D), Van Kien Pham ${ }^{2}$, Wing-Keung Wong ${ }^{3,4,5, *}$ and İsmail Bilgiçli 6 (iD) \\ 1 Department of Business Administration, Asia University, Taichung 41354, Taiwan; writetodrm@gmail.com \\ 2 International Economic Faculty, Banking University of Ho Chi Minh City, Ho Chi Minh 84, Vietnam; \\ kienpv@buh.edu.vn \\ 3 Department of Finance, , Fintech Center, and Big Data Research Center, Asia University, \\ Taichung 41354, Taiwan \\ 4 Department of Economics and Finance, Hang Seng Management College, Shatin 999077, Hong Kong, China \\ 5 Department of Economics, Lingnan University, Tuen Mun 999077, Hong Kong, China \\ 6 Tourism and Hotel Management, Sakarya Üniversitesi Esentepe Kampüsü, Serdivan/Sakarya 54050, Turkey; \\ bilgicli@sakarya.edu.tr \\ * Correspondence: wong@asia.edu.tw; Tel.: +886-4-2332-3456
}

Received: 27 October 2017; Accepted: 11 January 2018; Published: 17 January 2018

\begin{abstract}
This study proposes a new model by partially combining personality traits (PT) and Technology Acceptance Model (TAM) attributes to examine the influences of personality characteristics (conscientiousness, openness) and perception of technology (perceived usefulness, perceives ease of use) on e-purchase intention. We use truncate sampling technique and survey questionnaire to target the sample of Taiwanese online consumers and collect data. We find that consciousness (CON) (personality attribute) significantly influences perceived usefulness (PU) (technology perception attributes), perceived ease of use (PEOU) (technology perception attributes) and openness to experience (OPE) (personality attribute). PU, PEOU and OPE have significant impacts on e-purchase intention (INT). PEOU has the strongest positive impact on (INT). In addition, PU, PEOU and OPE combined together mediate the relationship between CON and INT. Further post hoc analysis of the mediation shows that both PU and PEOU are sustainable mediators. However, OPE is not a significant mediator.
\end{abstract}

Keywords: conscientiousness; openness to experience; perceived ease of use; perceived usefulness; online purchase intention

\section{Introduction}

Worldwide electronic commerce has significantly advanced due to the prominent development of the internet technology in the past decade. Internet technology has become a growing tool in providing variety website services [1]. Customers seek for products' features, price and functionality online. Consumers no longer need to go to physical stores to browse and compare prices to shop for goods [2]. Accordingly, internet technology has reshaped the way customers buy merchandises. The top categories of online sales are related to technological and electronic products, crafts, handmade products, accessories and clothes [3]. The direct influence of the components of the web marketing mix and purchase intention in China [4] indicates e-commerce in the Asia-Pacific region is becoming more and more popular.

E-commerce in the Asia-Pacific region has increased 30\% in 2013, accounting for over one-third of total e-commerce sales all over the world. In 2017, Taiwan's strong online infrastructure growth in terms of internet penetration and smartphone adoption surpasses some of Asia Pacific's key 
e-commerce markets including South Korea, Japan, Singapore and Hong Kong. As of 31 March 2017, Taiwan's internet penetration rate reaches $88 \%$ with more than 20,000,000 internet users [5]. Taiwan mobile-cellular telephone subscriptions get nearly 30,000,000 subscribers with $78.04 \%$ of the population using the Internet by the end of 2015 [6]. An average Taiwanese spent NT\$16,586 (US\$568) annually in 2012, rising from NT\$13,864 (US\$475) in 2010 on e-purchasing which accounts over $60 \%$ of online people for the whole country. Taiwan's online shopping market is growing rapidly. Therefore, it is important to determine which factors drive e-purchase intention of Taiwanese consumers.

According to Teresa, Bonnie, and Yingjiao [7], personality is one of the roots of understanding consumers' purchase intention. Personality is the internal force that motivates customers to affect a particular behavior and to unconsciously motivate customers. Therefore, marketers have to understand the effect of personality as a direct link to consumers' mind. Previous studies indicate that shoppers' character is a substantial factor for the success of e-vendors [8]. Online purchase intention has been described by different views, such as consuming in relative to demographical characteristics [9-12], emotional and psychological characteristics $[13,14]$, realizing positive and negative aspects of virtual transactions [15-18], shopping motivation [19,20] and orientation of purchasing [21]. Conscientious people are characterized as habitually focused, vigilant and well organized. Nevertheless, a few of the previous research has investigated the influence of conscientiousness on customers' e-purchase intention [22]. We believe the humanistic characteristics of a consciousness person are well matched with computer logarithm physiognomies that lead to the acceptance of technology.

Consuming behavior is sustainably influenced by individual characteristics of users [23]. Most authors conduct their studies under separate models of the Big Five Personality Trait Model [24] and Technology Acceptance Model [25] (Figure 1). Previous research has also studied purchase Intention [26]. However, as far as we know, there is no study in the literature to separate personality traits (PT) and then combine them with Technology Acceptance Model (TAM) to study the e-purchase intention (INT) of the consumers. In this paper, we bridge the gap in the literature to explore the most persuasive part of TAM and PT. We investigate e-purchase intention (INT) of the consumers; displayed as a new model in Figure 2 (we call it Model A). This study, therefore, examines the influence of the conscientiousness (CON) on e-purchase intention (INT) through perceived usefulness (PU), perceived ease of use (PEOU) and openness to experience (OPE). This paper attempts to allocate exclusive perceptions into the online shopping by discussing the determinative factors affecting buying intention of participants.

This study takes partially from the Technology Acceptance Model and partially from the Big Five Personality Trait Model. Conscientiousness is the propensity to show self-discipline and strive for aptitude and attainment [27]. It is one of the most sustainable personality predictors of attitude. Individuals perceive technology differently. Furthermore, the attributes of personality trait influence the way consumers shop online. This study aims at discovering how consumer's characteristics and perceptions about virtual vendors can be adjusted by personalizing e-vendors' environment. The aim is to find ways which encourage consumers and makes it easier for them to buy products online [8].

Taking into consideration the above-mentioned facts, this study provides the key for online sellers to comprehend e-purchase intention of customers. Previous research of individual's characteristics and perception of technology provides an essential ground tool for considering human behavior. As the most common model of personality traits, the Big Five model evaluates the most noticeable sides of personality [28]. Human's traits are basic constructing slabs of personality, which is more likely to lead constant shapes of person's thinking, feeling and manner [29]. In addition, the prototype of Big Five can confirm impacts of time's flow [30] as well as cultural exchanges [31]. The Big Five model elements include extraversion, conscientiousness, agreeableness, neuroticism (emotional stability) and openness to experience. In this paper, authors will limit the variables of personalities by using only conscientiousness as exogenous variable and openness to experiences as one of the mediating variables. Both variables, related to the area of personal behavior, interact and influence perception and use of technology. In traditional studies of The Big Five and consumer behavior the interaction 
of the variables might be different. This study explores and hints to the fact that in the new age of e-commerce and online shopping, unlike the traditional models, personality traits are NOT the sole influential elements. Technological perceptions for different age groups play an important role in consumer's e-purchase intention.

In this paper, we initiate the new concept of personality traits in conjunction with technology perceptions. We provide a better understanding of e-purchase intention behavior by looking at the sustainability and consistency of the mediating variables. Conscientiousness describes the reliability, responsibility, diligence and determination of an individual. The results also suggest that although consciousness people are attracted to shopping online, with the mediation of other factors such as openness to experience, perceived ease of use and perceived usefulness the influence of this personality trait becomes insignificant. This study is not product or service specific. Further product detailed analysis is necessary to make the practical implications of this study for specific products sold online.

The rest of this paper is structured as follows. Section 2 discusses the conceptual background of our study and sets all hypotheses that will be tested in our paper. Section 3 discusses the methodology being used in our study. Section 4 discusses our findings. Section 5 concludes the paper, discusses the inferences drawn from our findings and make implications from the findings of our paper.

\section{Conceptual Background and Hypotheses}

This study combines attributes of Technology Acceptance Model (TAM) and Personality Traits into a new model (Model A as shown in Figure 2). The aim is to have a better understanding of online shoppers' attitudes and e-purchase intention of consumers. The model proposed in this study (Model A) contains several factors as discussed in the following.

\subsection{Online Purchase Intention (INT)}

Online purchase intention reflects the desire of clients to buy through the internet. It is believed that a shopper is more likely to buy from virtual stores when e-commerce sites provide satisfactory tools including: products/services catalogues, searching functions, trust in websites, pricing comparison sheets, buying carts, online payment systems and outlining devices [32-35]. Thus, considering the importance of each corresponding factor plays an important role for online vendors to draw consumers and sustain sales. Purchase and repurchase intention refer to the outcome of consumers' intention to decide a particular action $[36,37]$ regarding the purchase of a product or service. Two main determinants of behavioral intention toward the aspects of personality are: shoppers' attitude and the subjective criteria [38]. Online shopping intention is the tendency of buyers to represent fixed behavior (i.e., buying) in fixed context (i.e., virtual stores). Pagani, Goldsmith, and Hofacker [39] (p. 252) suggest that combining internet users' personality traits and their perception of technology toward online shopping into one large category may lead to better understanding of human behavior. They suggest that understanding the elements of online users' interaction and intentions is necessary if "one wishes to study web-based phenomena, including social commerce".

\subsection{Perceived Usefulness (PU)}

The perceived benefits and sustainable advantages of shopping online are summarized as perceived usefulness. Finding bargain price in addition to the low cost of searching online can contribute to the notion of perceived usefulness. The advantages of purchasing from a virtual store compared to purchasing from a traditional store can also contribute to perceived usefulness. The effortlessness of comparing one virtual store to another virtual store is also another factor supporting the perceived usefulness [8]. E-commerce websites supply application software and helpful services that can facilitate shoppers' decisions of buying a product/service. Some services, however, may not be as convenient as in traditional market (e.g., immediate comparison among a variety of products that require tasting, smelling or sensing). Online shopping perceived usefulness 
could change consumers' attitudes toward purchasing [40]. Son et al. [41] assert that PU has a positive effect on consumer intention to use an internet application.

\subsection{Perceived Ease of Use (PEOU)}

PEOU refers to the extent to which a user perceives a particular technology, accessing websites, Internet functions and web-interface is easy to use [42]. It is about perceived necessary technological elements [43]. More specifically, a technology is more favorable for using than another if it is most likely to be approved by online shoppers. In other words, the more complicated a technological application is perceived to be, the more likely the website will be used. PEOU and PU are attributes of the acceptance of technology [41]. The PEOU construct has been used in various contexts such as electronic mail [44], e-commerce [16], m-commerce [45] and intention to use internet applications [46].

\subsection{Conscientiousness (CON)}

CON is identified by words of "precise", "efficient", "orderly" and "persistent". People with highly conscientious characteristic are often concentrated, careful, trustworthy and well organized, whereas unconscientious persons are most likely to express their distraction, disorganization and having flexibility [47]. It is believed that conscientious persons normally concern about factor of effectiveness. Conscientiousness describes the reliability, responsibility, diligence and determination of an individual [48]. Therefore, we believe that although $\mathrm{CON}$ is the major contributing factor of e-purchase intention; when mediated by PU, PEOU and OPE as indicated in Figure 2; the contribution is insignificant.

\subsection{Openness to Experience (OPE)}

According to the study of Migliore [47], open-minded persons to experience something new are individuals of intelligence, curiosity, free thought and flexible action. Researchers advocate that consumers" "openness to experience" is more inclined (lead by their willingness and flexibility to pursue multiple stimuli) towards Facebook, blog more and engage in various online activities [49-51]. Therefore, open-mindedness is a noteworthy forecaster of the overall virtual use. Also, open-minded persons are more likely to use an online shopping via the internet [52]. The result means that open-minded individuals are more likely to use e-purchase to confirm their inquisitiveness and find out freshly adventured practices [53].

\subsection{Development of Hypotheses}

Devaraj, Easley, and Crant [54] have successfully observed the support of conscientiousness in the relationship between perceived usefulness of technology and intentions to use the technology such that the relationship is stronger for individuals with higher conscientiousness. Another study done by Punnoose [55] also found that conscientiousness has a significant effect on PU. Based on previous studies, we propose the Hypothesis 1 (H1) as follows:

Hypothesis 1. CON has a positive association with $\mathrm{PU}$.

Closed people refer to those who have a simple, plain and straightforward mind. Using new technology is not easy for closed people right from the start. With lacking interest in the variety of new software a certain level of PEOU will not be enough to build up an intention to use the technology. On the other hand, open people like to spend time reflecting on new technology and new products. They enjoy unusual interaction and are willing to overcome any possible challenge when using new technology. Svendsen et al. [56] suggest that there is a positive relationship between OPE and PEOU. This idea is also supported by other researchers. For example, Shambare [57] finds a significant positive effect of OPE on PEOU. Rosen and Kluemper [58] conclude that CON significantly influences PEOU in acceptance of social networking websites technology. In previous studies the internal relationship 
between CON and OPE has been ignored. Thus, we set to test the following two hypotheses for e-purchase intention:

Hypothesis 2. CON has positive association with PEOU.

Hypothesis 3. CON has positive association with OPE.

Research on the different variables of the TAM reveals significant relationships between PEOU, PU and INT. Davis [42] argues that PEOU and PU jointly influence behavioral intentions. Kim and Song [59] propose that perceived usefulness is related to purchase attitude among online shoppers. If consumers find an e-commerce website useful for shopping, they will advantageously have a better e-purchasing attitude. Other studies by Yoon and Steege [60], Punnoose [55], Aldás-Manzano et al. [61], Özbeka et al. [62] and Devaraj [54] also confirm the relationship between PU and INT. Several researchers have found a positive relation between the PEOU and INT. Childers et al. [63] suggest that clear and understandable online shopping sites, which require less mental efforts of their users to make a purchase, are more attractive for potential customers than more complicated ones. Marjan et al. [64] suggest that clients with "perceived ease of use" tend to have a higher intention of buying goods from virtual stores. Thus, the ease of use relating to e-commerce website's functions and interfaces is useful in the forecasting of users' intention towards e-purchase. Perceived ease of use is highly relevant to clients' manner in experience online shopping accordingly to applications of the internet, which is strongly associated with intention to purchase. Thus, we propose the following hypothesis:

Hypothesis 4. PU has positive association with INT.

Hypothesis 5. PEOU has positive association with INT.

Thorbjørnsen et al. [65] indicate that social identity expressiveness is positively related to intention to use multimedia messaging. Based on Mowen's hierarchical model of personality, Bosnjak et al. [66] explain and predict people's disposition to use e-purchases [67]. Almost all elements have positive relationships, including the relationship between conscientiousness and openness to experiences. This paper uses a hierarchy model with the following hierarchy: surface, situational, compound and elemental. CON and OPE are among the basic hierarchical and elemental characteristics included in the Big Five dimensions of characters [67]. Figure 1 shows the interrelations among the major three factors. Based on this model and recent studies [68], we propose the following two hypotheses.

Hypothesis 6. OPE has positive association with INT.

Hypothesis 7. CON has positive association with INT.

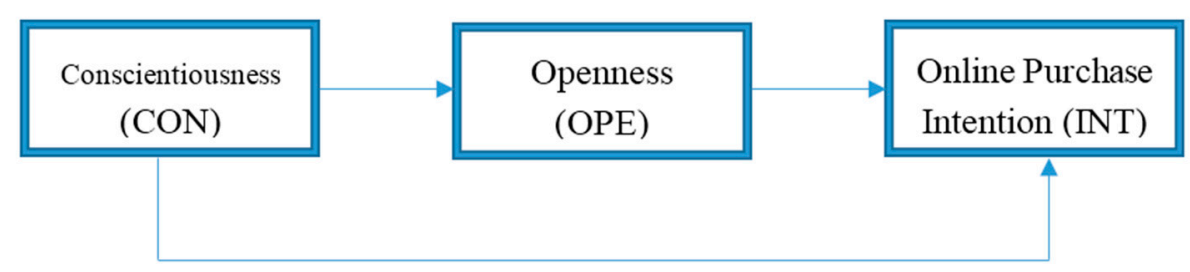

Figure 1. The relationships among CON, OPE and INT [67].

Technology Acceptance Model posits that perceived PU and PEOU determine an individual's intention to use a system, with the intention to use serving as a mediator of actual system use [42]. Previous studies test the mediating effect of PEOU and PU of behavioral intention [69]. However, to the 
best of our knowledge, there is no empirical study that tests the mediating effect in the relationship between personality traits and e-purchase intention. Thus, we set the following hypothesis:

Hypothesis 8. PU, PEOU and OPE mediate the relationship between CON and INT.

\subsection{Theoretical Framework and Hypotheses}

The theoretical framework paves the way for the study hypotheses that examine the interrelations among the variables being studied. The framework hypothesizes that personality traits can affect online purchase intention. The model (Model A), depicted in Figure 2, suggests that e-purchase intention (INT) is the endogenous variable which is influenced by the CON as an exogenous variable. Moreover, it is assumed that the effect of CON on INT is fully mediated by PU, PEOU and OPE:

$$
\text { Model A: } \eta=f\left(\xi_{1}, \xi_{2}, \xi_{3}, \xi_{4}\right)
$$

where $\eta$ is e-purchase intention (INT), $\xi_{1}$ be perceived usefulness (PU), $\xi_{2}$ be perceived ease of use (PEOU), $\xi_{3}$ be openness to experience (OPE) and $\xi_{4}$ be conscientiousness (CON). PU, PEOU and OPE are not only the endogenous variables but also the mediators for $\eta$. The equation can be exhibited in Figure 2.

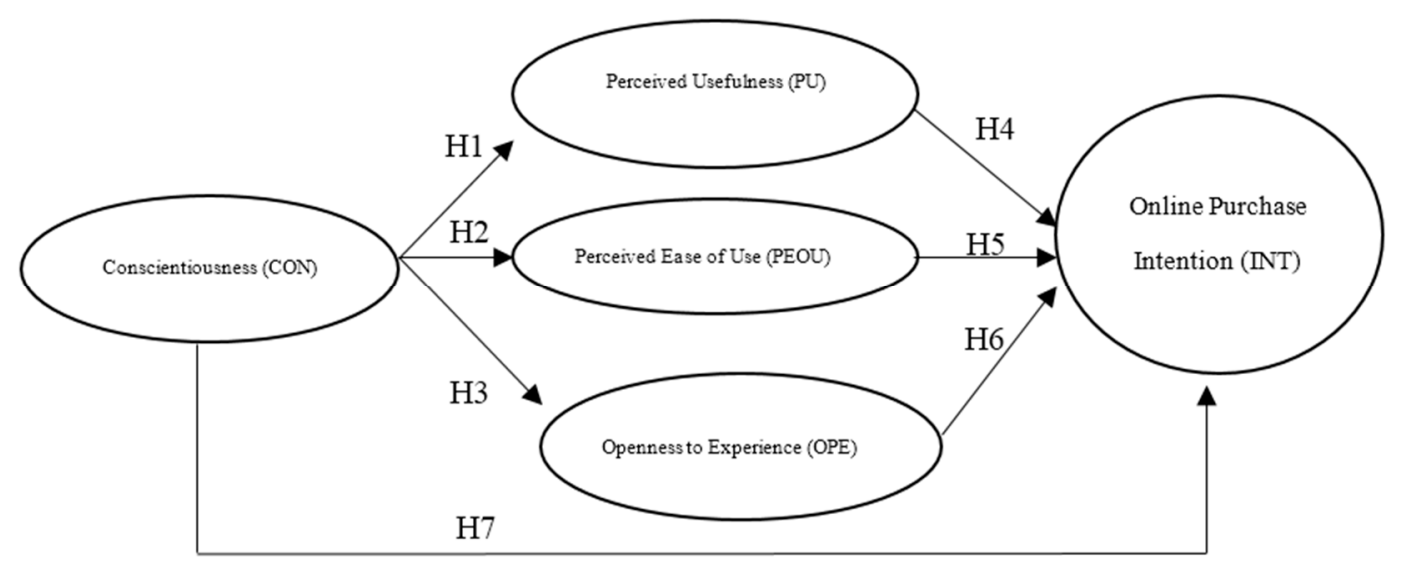

Figure 2. Model A.

\section{Research Methodology}

In the current study, we researched questionnaires from the previous literature review. Then, we modified the questionnaires to fit into our study in Taiwan. The purpose of the questionnaire is to evaluate the present situation about e-shopping purchase of Taiwanese. Survey instrument is then used in order to study influential attributes of personality and technology on e-purchase intention. In this section, we describe quantitative data analysis process. The results of statistical analysis will help to make the conclusions to obtain a general overview of the entire research model.

\subsection{Sample Selection}

This project involves the collection of empirical data regarding e-purchase. The population of this research is Taiwanese online shoppers. It is common for Taiwanese, under the age of 50 and above the legal age to shop online and to use technological applications to purchase products or services on virtual stores. Consumers who are more comfortable to access technological applications possess certain characteristics. These characteristics will lead to online shopping decisions and creates a potential e-commerce market [70]. We use truncated sampling technique to collect 380 data. The calculation of sample size is based on confidence level of $95 \%$, Taiwanese population (15-45) of 10,402,409 [71] 
and confidence internal (margin of error) of 5\%. A total of 316 (out of 380) usable questionnaires from Taiwanese consumers aged from 16 to 45 -year-old is collected. We call this sampling technique "truncated sampling" [72] because the data is truncated to observations from 16 to 45 -year-old.

The survey questionnaires of this paper are built fundamentally by the features which are chosen based on considerations for the research framework, definition of the variables and literature reviews. Most of the items on the instrument are based on questions used in previous research. Some questions are used in their original form while others are modified slightly to address the specific nature of this study. In the design of a questionnaire for our survey, a complex construct is used so that it is rich in both meaning and multi-dimensional. As shown in Table 1, multiple measures are employed to evaluate the attributes suggested in the previous section, CON (three variables, CON1 CON3), PU (three variables, PU1 PU3), PEOU (three variables, PEOU1 PEOU3), OPE (four variables, OPE1 OPE4) and IN (two variables, IN1 IN2). Table 1 shows the brief descriptions of these variables used in our questionnaire. Our questionnaire containing research questions related to those hypotheses proposed in Section 2 were first circulated to consumers using simple random sampling technique [73]. Respondents were requested to access various attributes with respect to e-purchase and e-service. In order to assess consumers e-purchases and use of e-services, the respondents were also asked to divulge the extent to which they actually use Internet services within a particular period of time. Because Internet users are likely to appreciate the idea of e-purchase and e-service, they should be able to give reasonable expectations in response to our research questions. We "truncate" Taiwanese consumers aged between 16 and 45 years old who possess experiences with e-purchases and e-services. We call this sampling technique "truncated sampling" [72] because the data is truncated to observations from 16 to 45 year-olds who possess experiences with e-purchases. We use the Likert's scale for all of the research questions including five scores ranking from 1 to 5 in which scores 1 and 5 are corresponding to "strongly disagree" and "strongly agree," respectively. Using the truncated sampling technique, we collect 380 data and eventually choose a total of 316 (out of 380) usable questionnaires.

Table 1. Summary of Reliability and Validity.

\begin{tabular}{|c|c|c|c|c|c|c|}
\hline \multirow{2}{*}{ Variables } & \multirow{2}{*}{ Items * } & \multirow{2}{*}{$\mathbf{M}$} & \multirow{2}{*}{ SD } & \multicolumn{2}{|c|}{ Factor Loadings } & \multirow{2}{*}{ Cronbach's Alpha } \\
\hline & & & & Model & CFA & \\
\hline \multirow{3}{*}{$\mathrm{CON}$} & CON1 & 3.728 & 0.778 & 0.695 & 0.694 & \multirow{3}{*}{0.781} \\
\hline & CON2 & 3.661 & 0.741 & 0.786 & 0.788 & \\
\hline & CON3 & 3.655 & 0.819 & 0.731 & 0.734 & \\
\hline \multirow{3}{*}{ PU } & PU1 & 3.769 & 0.936 & 0.772 & 0.773 & \multirow{3}{*}{0.823} \\
\hline & PU2 & 3.687 & 0.902 & 0.732 & 0.740 & \\
\hline & PU3 & 3.873 & 0.875 & 0.84 & 0.831 & \\
\hline \multirow{3}{*}{ PEOU } & PEOU1 & 3.718 & 0.866 & 0.898 & 0.899 & \multirow{3}{*}{0.906} \\
\hline & PEOU2 & 3.750 & 0.849 & 0.917 & 0.915 & \\
\hline & PEOU3 & 3.766 & 0.794 & 0.809 & 0.811 & \\
\hline \multirow{4}{*}{ OPE } & OPE1 & 3.392 & 0.879 & 0.787 & 0.787 & \multirow{4}{*}{0.885} \\
\hline & OPE2 & 3.475 & 0.818 & 0.857 & 0.858 & \\
\hline & OPE3 & 3.415 & 0.833 & 0.940 & 0.939 & \\
\hline & OPE4 & 3.076 & 0.960 & 0.689 & 0.689 & \\
\hline \multirow{2}{*}{ INT } & INT1 & 3.994 & 0.866 & 0.547 & 0.551 & \multirow{2}{*}{0.640} \\
\hline & INT2 & 3.915 & 0.924 & 0.853 & 0.856 & \\
\hline \multirow{2}{*}{ Instrument Total } & KMO & & 0.796 & & & \multirow{2}{*}{0.815} \\
\hline & $p$-value & & 0.000 & & & \\
\hline
\end{tabular}

* Item details are as follows: CON: I see myself as someone who . . ; CON1: does a thorough job; CON2: can be somewhat careless; CON3: is a reliable worker. PU [42]: Online shopping ... ; PU1: helps me to make purchases faster; PU2: helps me to make cheaper purchases; PU3: makes it easier for me to make purchases. PEOU [42]: Online shopping ... ; PEOU1: instructions are easy to follow; PEOU2: is easy to learn how to use; PEOU3: websites are easy to operate. OPE [31]: I see myself as someone who ...; OPE1: is original and comes up with new ideas; OPE2: is curious about many different things; OPE3: is ingenious and a deep thinker; OPE4: has an active imagination. INT [38]: Online shopping ... ; INT1: helps me to make purchases faster; INT2: helps me to make cheaper purchases. 


\subsection{Research Model}

Equation (1) is the mathematical model. To estimate the parameter in Equation (1), we need to obtain the data while $\eta$ is a latent endogenous variable of the observable variable $y$ and thus, there is an error to measure the latent variable. In addition, all the exogenous variables $\xi_{1}, \xi_{2}, \xi_{3}$ and $\xi_{4}$ are latent and thus, Equation (1) become

$$
y=f\left(\xi_{1}, \xi_{2}, \xi_{3}, \xi_{4}\right)+\zeta=\eta+\zeta
$$

where $\zeta$ is an error term with $\Sigma=\operatorname{Cov}(\zeta)$. Since all the exogenous variables $\xi_{1}, \xi_{2}, \xi_{3}$ and $\xi_{4}$ are hypothesized to lead to the latent $\eta$ of endogenous variable $y$ positively, we assume:

$$
\partial \eta / \partial \xi_{i}>0 i=1,2,3,4 .
$$

We use the following linear structural econometric model to approximate Equation (2):

$$
y=\Gamma \xi+\zeta
$$

where $\xi=\left[\xi_{1}, \xi_{2}, \xi_{3}, \xi_{4}\right]^{\prime}$ the endogenous variable, $y$, is observable but all the exogenous variables $\xi_{1}, \xi_{2}, \xi_{3}$ and $\xi_{4}$ are unobservable. As such, several said $n_{i}$, of observed items of $x_{i},\left(x_{i j}, j=1, \ldots, n_{i}\right)$ are used to measure $\xi_{i}$ for each $i=1,2,3$ and 4 . The measurement model for the exogenous latent variables is:

$$
x=\Lambda_{x} \xi+\delta
$$

where, $x=\left[x_{11}, x_{12}, \ldots, x_{1 n 1}, x_{21}, x_{22}, \ldots, x_{2 n 2}, x_{31}, x_{32}, \ldots, x_{3 n 3}, x_{41}, x_{42}, \ldots, x_{4 n 4}\right]^{\prime}$ and $\xi=\left[\xi_{1}, \xi_{2}, \xi_{3}, \xi_{4}\right]^{\prime}$.

We estimate the model in (2), we employ the exploratory factor analysis to examine all the items within the four exogenous variables and the endogenous variable to obtain the factor loadings. The reliability analysis is then applied to examine the reliability of the items. Thereafter, the structural equation model of the path analysis is used to perform confirmatory factor analysis (CFA) on the hypothesized model in Figure 2.

\subsection{Data Analysis Procedure}

Descriptive statistics show the value of the personality measure for every personality dimensions. To measure the factor loading, EFA (Explored Factor Analysis) and CFA (Confirmatory Factor Analysis) are employed. Structural equation modeling (SEM) allows the concurrent estimation of multiple multivariate equations. It consists of factor analysis, multiple regression analysis and path model analysis [74]. Path analysis of the hypothesized structural model, EFA, CFA, mediation analysis, validity and reliability estimates are performed by using SPSS 22 and AMOS 22.

\section{Result and Findings}

\subsection{Demographic Characteristic}

In this study, 316 usable survey questionnaires are gathered from Taiwanese consumers. The demographic information of the respondents includes: gender (Female, 59.5\%) and age (16-25, $54.1 \% ; 26-45,45.9 \%$ ). Regarding the age of online shoppers, up to $94.9 \%$ are youngsters from 16 to 35 . With regard to the educational level, the study indicates that most of the respondents are educated beyond high school (90.2\%).

\subsection{Test of Reliability and Validity}

Reliability and Validity tests are used to test whether the data are reliable and valid. The tests are the essential part of all research designs and although distinct, they are often discussed together [75]. The reliability coefficient of Cronbach's alpha conducted is obtained to evaluate internal consistency 
among the survey instruments. If the value of coefficient alpha is between 0.6 and 0.8 and Factor loadings should be 0.5 or higher, the instrument is considered reliable and an $\alpha$ value over 0.8 is considered highly reliable [76]. The results of the reliability test indicate that all constructs and the instrument are reliable or highly reliable (Table 1).

Validity test is completed by exploratory factor analysis which is known as an important tool for researchers since it can be useful for refining measures, evaluating constructing validity and in some cases testing hypotheses [77]. In so doing, this study uses KMO and Bartlett's Test of Sphericity to test the validity of the instrument.

As a result, and shown in Table 1, all factor loadings are higher than 0.5. For the KMO measure of sampling adequacy, in this analysis the KMO is 0.84 which is higher than 0.6. The chi-square $\chi^{2}=3133.25$, significant with $\rho<001$. All factor loadings are above 0.5 . In conclusion, the constructs used in this study are valid and the results from factor analysis can be used for further analysis.

\subsection{Confirmatory Factor Analysis (CFA)}

In this process, all variables are included as exogenous variables in the proposed model using AMOS 22. In EFA, we explore factor structure while in CFA, we confirm the factor structure we extracted from EFA to improve the overall model fit of the model. The CFA results indicate that Chi-square/Degrees of freedom $\left(\chi^{2} / \mathrm{df}\right)=1.54$. The GFI (goodness of fit index $)=0.95$. The results meet the criteria of a good model fitting suggested by Bentler and Bonnet [78] and others. It is commonly agreed [79] that the comparative fit index (CFI) should be greater than 0.90 to indicate well fit. In this study, the CFI $=0.98$, implying our model fits the data very well. The Tucker-Lewis coefficient (TLI) $=0.98$. TLI value is close to 1, indicating a very good fit [78]. In addition, MacCallum, Browne, and Sugawara [80] suggest that it is an adequate fit if the root mean square error of approximation (RMSEA) is less than 0.08 . In this paper, the RMSEA $=0.04$. Thus, all the model fit indices of this study indicate a good fit for the structural model.

\subsection{Composite Reliability, Convergent and Discriminant Validity}

Convergent Validity is the extent to which indicators of a specific variable 'converge' or share a high proportion of variance in common. Convergent Validity consists of two items: composite reliability (CR) and average variance extracted (AVE). CR is a measure of reliability and internal consistency based on the square of the total of factor loadings for a construct [81]. On the other hand, AVE is a summary measure of convergence among a set of items representing a variable [82]. It is the average percent of variation explained among the items [74,81]. As suggested by Anderson and Gerbing [81], the CR should be greater than 0.7 while Fornell and Larcker [82] suggest AVE to be at least 0.5 .

Besides CR and AVE as discussed before, there are a few measures that are useful for establishing validity and reliability: maximum shared variance (MSV), maximum reliability (Max R) and maximum inter-construct correlation (Max r). As indicated in Table 2 for all variables: CR $>0.7$, AVE $>0.5$, MSV $<$ AVE and $\sqrt{ }$ AVE $>$ Max correlation [74,82]. The results of Table 2 indicate the validity and reliability of the instrument and the CFA. Fornell and Larcker [82] suggest comparing the square root of AVE with the maximum correlation coefficients of latent variables. The result indicates that $\sqrt{ }$ AVE $>$ Max $r$ (Table 2). The findings of all indicators provide the evidence supporting the reliability and validity of the indicators of the proposed model.

Table 2. Test of Composite Reliability, Convergent Validity, and Discriminant Validity.

\begin{tabular}{ccccccccccc}
\hline & CR & AVE & MSV & Max R & Max r & PEOU & CON & OPE & PU & INT \\
\hline PEOU & 0.908 & 0.768 & 0.444 & 0.919 & 0.666 & 0.876 & & & & \\
CON & 0.783 & 0.547 & 0.099 & 0.938 & 0.315 & 0.315 & 0.740 & & & \\
OPE & 0.893 & 0.678 & 0.068 & 0.965 & 0.260 & 0.070 & 0.260 & 0.823 & & \\
PU & 0.825 & 0.612 & 0.088 & 0.970 & 0.296 & 0.251 & 0.280 & 0.164 & 0.782 & \\
INT & 0.701 & 0.518 & 0.444 & 0.973 & 0.666 & 0.666 & 0.211 & 0.038 & 0.296 & 0.720 \\
\hline \multicolumn{10}{c}{ CR $>0.7 ;$ AVE $>0.5 ;$ MSV < AVE; $\sqrt{ }$ AVE $>$ Max ; $\sqrt{ }$ AVE is bold face diagonal. } &
\end{tabular}




\subsection{Test of Hypotheses}

We employ Structural Equation Modeling (SEM) technique to analyze the measurement model, estimate the structural model and test the proposed research hypotheses. The fitted structural model indicates the following values: $\mathrm{CMIN} / \mathrm{DF}=1.54$, which complies with the suggested criteria of $<3$, Goodness of Fit Index (GFI) $=0.95$, Comparative Fit Index $(\mathrm{CFI})=0.98$ and Root Mean Square Error of Approximation (RMSEA) $=0.04$. The results shown in the structural model meet the minimum requirement of acceptable values, indicating a good fit of the conceptual model on the empirical data in this study.

Table 3 presents the result of the proposed hypotheses for the proposed research model. From the table, we find that $\mathrm{H} 1, \mathrm{H} 2, \mathrm{H} 3, \mathrm{H} 4$, and $\mathrm{H} 5$ are supported but $\mathrm{H} 6$ and $\mathrm{H} 7$ are rejected in the research model. The H1 is supported because CON shows positive $(\beta=0.41)$ and significant $(p<0.001)$ effect on PU. From this result, we can conclude that CON has a significantly positive effect on PU. Similarly, CON also shows significantly positive effects on both PEOU $(\beta=0.39)$ and OPE $(\beta=0.32)$ with significance level $p<0.001$, implying both $\mathrm{H} 2$ and $\mathrm{H} 3$ are supported. Both PU and PEOU indicate significant impacts on INT with $\beta=0.17(p<0.05)$ and $0.79(p<0.001)$, respectively. OPE, however, does not influence INT significantly, resulting in the rejection of H6. The indirect influence of CON on INT (H7) with the presence of the mediating variables (PU, PEOU, OPE) is rejected with $\beta=0.01(p>0.05)$. The influence of CON on INT is supported without the presence of the mediators is significant $(\beta=0.28$, $p<0.01$ ) (Figure 3). This suggests the existence of significant mediating effects as stated in the H8.

Table 3. Results of the hypotheses.

\begin{tabular}{cccc}
\hline Hypothesis & Description & Estimate & Results \\
\hline H1 & CON $\rightarrow$ PU & $0.41^{* * *}$ & Supported \\
H2 & CON $\rightarrow$ PEOU & $0.39^{* * *}$ & Supported \\
H3 & CON $\rightarrow$ OPE & $0.32^{* * *}$ & Supported \\
H4 & PU $\rightarrow$ INT & $0.17^{*}$ & Supported \\
H5 & PEOU $\rightarrow$ INT & $0.79^{* * *}$ & Supported \\
H6 & OPE $\rightarrow$ INT & -0.03 & Rejected \\
H7 & CON $\rightarrow$ INT (with mediation of PU, PEOU, INT) & 0.01 & Rejected \\
\hline \multicolumn{4}{c}{}
\end{tabular}

The mediating test of the PU, PEOU and OPE indicates significant full mediation with the presence of the three mediating variables. Therefore, $\mathrm{H} 8$ is supported as shown in Table 4 . This result prompts us to look at each mediator separately to have a better understanding of all the mediation effects. The post hoc analysis of the mediation indicates that both PU and PEOU act as significant mediators between $\mathrm{CON}$ and INT. However, OPE is not a significant mediator. Figure 3 provides a visual representation of the proposed eight hypotheses of the study.

Table 4. Results of the mediation hypotheses.

\begin{tabular}{cccccc}
\hline & & Indirect $(\mathbf{a b})$ & Direct $\left(\mathbf{c}^{\prime}\right)$ & Total $(\mathbf{c})$ & Mediation \\
\hline $\mathrm{H} 8$ & $\mathrm{CON} \rightarrow(\mathrm{PU}, \mathrm{PEOU}, \mathrm{OPE}) \rightarrow \mathrm{INT}$ & $0.31^{* * *}$ & $0.01(\mathrm{NS})$ & $0.32^{* * *}$ & Supported \\
$\mathrm{H} 8 \mathrm{a}$ & $\mathrm{CON} \rightarrow \mathrm{PU} \rightarrow \mathrm{INT}$ & $0.09^{* *}$ & $0.2(\mathrm{NS})$ & $0.29^{* *}$ & Supported \\
$\mathrm{H} 8 \mathrm{~b}$ & $\mathrm{CON} \rightarrow \mathrm{PEOU} \rightarrow \mathrm{INT}$ & $0.30^{* * *}$ & $0.01(\mathrm{NS})$ & $0.31^{*}$ & Supported \\
$\mathrm{H} 8 \mathrm{c}$ & $\mathrm{CON} \rightarrow \mathrm{OPE} \rightarrow \mathrm{INT}$ & $0.01(\mathrm{NS})$ & $0.27^{* *}$ & $0.28^{* *}$ & Rejected \\
\hline \multicolumn{5}{r}{$p<0.05,{ }^{* *} p<0.01,{ }^{* * *} p<0.001}$.
\end{tabular}




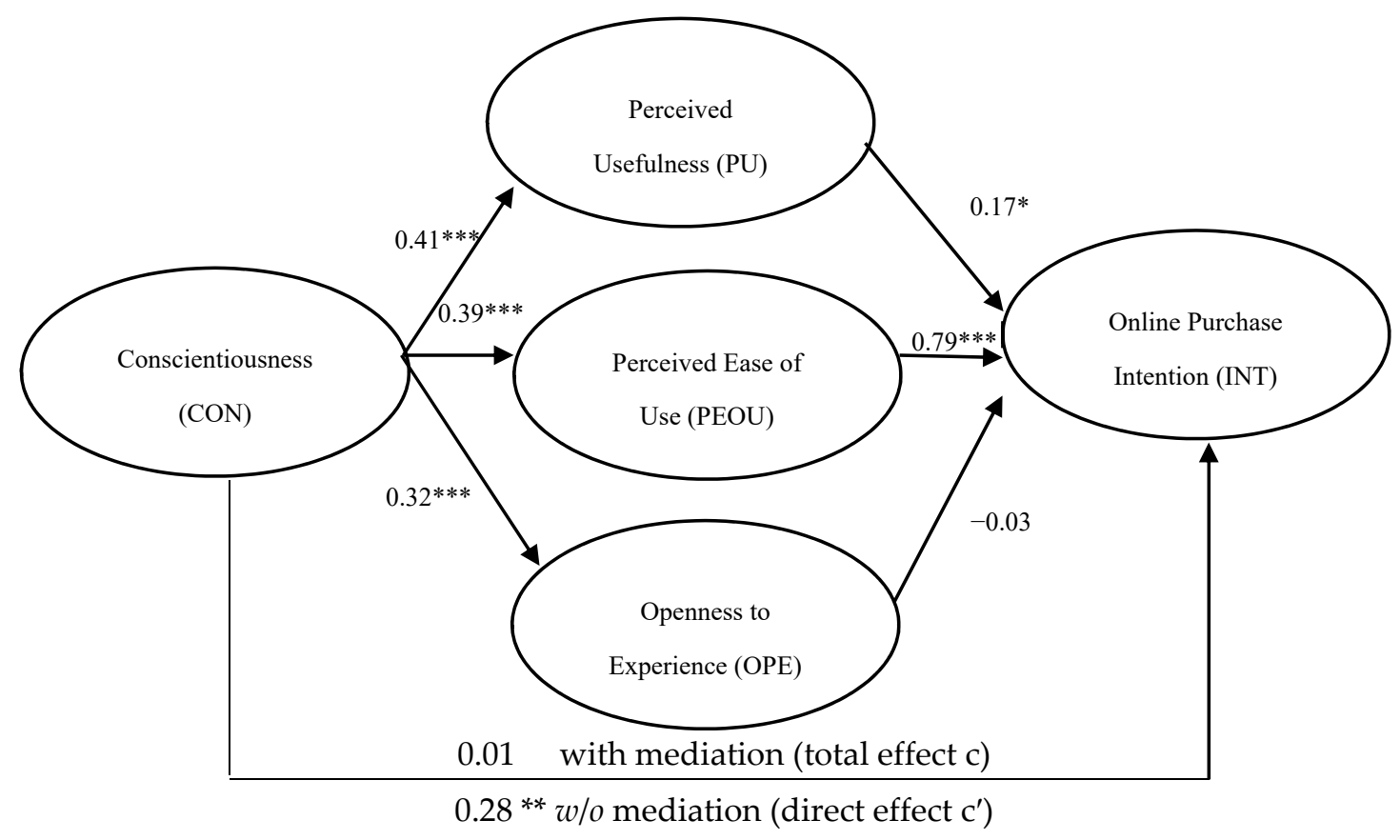

Figure 3. Result of Hypothesis Test. ${ }^{*} p<0.05,{ }^{* *} p<0.01,{ }^{* * *} p<0.001$.

\section{Discussion, Conclusions and Managerial Implications}

\subsection{Discussion and Conclusions}

There are some papers that study about personality traits and technology perception as they relate to online purchase intention. However, most of those studies ignore the mediating effects of some factors such as perceived usefulness, perceived ease of use and openness to experience related to personality traits. For these reasons, this study extends previous works by first combining personality traits and technology perception to offers a total of eight hypotheses. These hypotheses are created and tested by using the multiple regression analysis. The purpose of this research is to test the direct relationship between the exogenous variables (CON, PU, PEOU and OPE) and endogenous variable (INT). Furthermore, we investigate the indirect relationship between CON and INT through the mediation roles of PU, PEOU and OPE. The final results indicate that all hypotheses are supported except the mediating role of OPE. We will discuss every single hypothesis as follows.

$\mathrm{H} 1 \mathrm{CON}$ has a significant influence on PU. This finding is consistent with previous works like Devaraj et al. [54], Punnoose [55] and others that support the significant connection between CON and PU. Intentions to experience the technology is stronger for individuals with higher conscientiousness. This study extends the previous findings to show the influence of CON on INT through PU. Costa and McCrae [31] characterize CON personality trait as being about people who are naturally motived and those who strive to aim at achievements at a high level and perform positive actions. The signs of CON person are self-control reflected in a need for performance, order and persistence. Therefore, in the proposed model of this study, CON represents an intrinsically driving force for toward the e-purchase. Conscientious people are cautious when reviewing whether technological applications will allow them to be more effective. On the other hand, if a conscientiousness person concludes that a technology is not beneficial, then he or she will not use it [54].

$\mathrm{H} 2 \mathrm{CON}$ has a significant impact on PEOU. CON is the characteristic of people who think everything inside out with persistence and caution. Is the characteristic of a person expecting that actions will end with the highest possible results? Person of CON is often efficient and ordered as opposed to free and easy. It means that this person who is generally organized and dependable will perform actions based on a clear and particular schedule instead of immediately thought. PEOU refers 
to technologies and interfaces on e-commerce websites which is more favorable to access than another is more likely to be accepted by the participants. Since they are very precise, perfectionistic and effective, they prefer something that is very efficient to use. When they look for a website, they will eagerly compare some features that make the website easier to understand and thus, more efficient to use. They are very aware of the usefulness of the feature of the website. For these reasons, online shopping websites have to create improvement on the usefulness to attract conscientiousness online shoppers by performing time and money saving, quick service, low risks, etc.

$\mathrm{H} 3$ states that CON significantly influences OPE. Conscientious personalities usually are very concerned about effectiveness, while OPE is implied as being intellectually curious, open to new ideas, involves imaginative and creative cognition styles [47]. Thus, CON personalities have to be more open to new ideas which make their life become more efficient when they use the approach of online purchasing. This study extends the previous research to show the internal relationship of personality characters toward e-purchase intention.

H4 shows that PU has a significant impact on INT. Previous studies indicate that shoppers' PU of an online store positively influences their buying intention and repurchase intention in the future. Online purchase intention is determined by perceived usefulness of technological innovation $[43,83]$. The results of this study imply that Taiwanese customers who perceive technology as a useful tool for shopping online tend to use more online for their purchase. The result is consistent with studies of Aldás-Manzano et al. [61] and Yoon and Steege [60]. They find that online shoppers in different countries have the same expectation of looking for advantages of purchase via the internet by themselves. As a result, PU is one of the major key drivers of usage behavior and intention to purchase.

H5 states that PEOU has a significant influence on INT. Therefore, technologies which are perceived as easy to use will stimulate customers to purchase online. In addition, Childers et al. [63] argue that clear and understandable online shopping sites, which require less mental efforts to make a purchase, are more attractive for potential customers than more complicated ones [63]. This finding is very important since online shoppers reveal that the conveniences of websites, which are free from effort in order to make an order, are part of the main factors to make virtual store to be successful.

H6 states that OPE is a sustainably determining factor related to INT. People with high OPE are more likely to explore something new and thus, like to participate in e-activities. As proposed by Tuten and Bosnjak [53], it is reasonable to meet the need of this type of people and find out new adventurous way for them. OPE is one of the important forecasting elements influencing the growth of internet's applications [52]. It means that people who exhibit this type of personality trait (openness) would prefer to purchase online than go to the traditional stores. The results are in accordance with Arnold and Reynolds [84] who argue that a person with higher level of OPE is more likely to buy goods and get services in virtual stores.

H7 formulates that CON has a significant impact on INT. The awareness of high conscientious people is very high. They prefer to make themselves to do something that is more efficient and well organized. They like to do something orderly but not something spontaneously. There is a possibility that conscientious people prefer online shopping to traditional practices since online shopping is a method that is more organized, more efficient and more specific. Moreover, going to the traditional stores that requires staying in traffic, wandering around and could end up wasting time with the possibility of buying nothing is not attractive to conscientious people. While online store provides more detailed information about prices, products and how to buy something without going to the shops but delivering to the destination place. Thus, it helps online buyers to compare the prices and products from one website to another and help them to consume products or get services that match with their need. Hence, it will be more comfortable and more effective for those who seek for efficiency and precisely.

H8 states that PU, PEOU and OPE mediate the relationship between CON and INT. As a result, both PU and PEOU play an important role of full mediators in the relationship between CON and INT while OPE does not. As discussed in the theoretical section, PU, perceived usefulness of purchasing 
from an online store, is known as the perceived benefits and the overall perceived advantages of online shopping sites. PEOU, perceived ease of use, is about perceived necessary technological elements approved by online shoppers. Obviously, the influence of conscientiousness on online purchase intention is strongly meditated by the benefits and technological elements that an online store provides to customers. Therefore, online shopping service providers should highly focus on the improvement of the latest and advanced technology that enables online shoppers to purchase goods or get services easily. Furthermore, in order to increase the benefits perceived from buyers, online shopping service providers need to provide easy ordering, convenient delivery, customer training, customer consulting, maintenance and repair, returns, etc. The findings also indicate existence of a non-mediating effect of OPE. In other words, openness to experience, in the presence of PU and PEOU, is not a good mediator in the relationship between CON and INT as found out in the proposed model of this study. Thus, it is important for virtual stores to put more emphasis on PU and PEOU when they observe the influences of conscientious factor on online purchase intention.

In conclusion, our study successfully explores the direct and indirect influence of both CON on INT under the sample of Taiwanese online shoppers. Our findings provide many significant applications that advice online shopping service providers need to study clearly about conscientiousness personality of online shoppers to draw purchase intention from them. In doing so, online shopping sites should focus on utility-motivated factors like technology throughout the process of online shopping. Since consumers that have conscientiousness personality often use their knowledge to carefully access if products or services bring them the desired values.

\subsection{Managerial Applications}

This research shows evidence that personal traits are important determinants affecting e-shoppers' buying intention. As a result, it is a noteworthy background toward studying the field of online consuming behavior. Actually, online vendors can use the result as fundamental reference material to plan an effective consumer-oriented strategy and attract more consumers to buy goods and get services online. The results also suggest that although consciousness people are attracted to shopping online, with the mediation of other factors such as openness to experience, perceived ease of use and perceived usefulness, the influence of this personality trait becomes insignificant. Online shoppers' intention to purchase online will increase through perceived usefulness, perceived ease of use and their openness to experience of new technology. Therefore, online store owners and web designers can attract consciousness people by increasing easy and useful functions during the process of purchasing such as ease of order, ease of payment, time and money savings, while considering the other personality trait like openness to experience. Therefore, this research is a good reference for web designers, online shopping vendors and technological applications and software providers. Specifically, the web-designers need to create eye-catching sales interface of websites. Additionally, website owners have to come up with smart tools and functionalities of the technological applications to help users go online shopping easily even unprecedented access to technology previously. Duties of online providers is to find ways to encourage customers' interest in the products and services in their virtual stores by providing online shoppers easy and useful purchasing service with obvious and detailed information including products, prices, promotions, delivery, installation, warranty, guarantee, etc. It is the aim of this study to aid online vendors in using the findings in our study effectively to draw online purchase intention from conscientiousness consumers.

Last, we note that is worthwhile investigating whether the findings in our paper are consistent in some sub-samples, like dividing the sample into two subsamples and analyzing different groups based on gender, age group and income, to name a few. In addition, it is common that after one interesting case study paper published, there are many papers extend the work to use different samples to show that the results are not, by chance, confirming the theory. Hence, extensions may include comparison with any other samples. Readers may refer to Wong et al. [85] and the references therein for more information on the discussion. 
Acknowledgments: The authors are grateful to the Editor-in-Chief, Marc A. Rosen, the Guest Editors, Chia-Lin Chang and Michael McAleer, and two anonymous referees for constructive comments and suggestions that led to a significant improvement of an early manuscript. The third author would like to thank Professors Robert B. Miller and Howard E. Thompson for their continuous guidance and encouragement. This research has been partially supported by Asia University, Banking University of Ho Chi Minh City, China Medical University Hospital, Hang Seng Management College, Lingnan University, the Research Grants Council (RGC) of Hong Kong (project number 12500915), and Ministry of Science and Technology (MOST), R.O.C.

Author Contributions: Massoud Moslehpour initiate the ideas, formulate the problems, do detailed planning, develop the theory, developed the initial research model and conduct the initial analysis. Van Kien Pham improved the research model, conduct the analysis and write up the first draft. Wing-Keung Wong assist Massoud Moslehpour to further formulate the problems, do detailed planning, and improve the theory, and make the theory more advanced, and check the final research model and statistical analyses İsmail Bilgiçli assists us to write up and help proof read our paper.

Conflicts of Interest: The authors declare no conflict of interest.

\section{References}

1. Rodríguez Bolívar, M.P. Policy makers' perceptions on the transformational effect of Web 2.0 technologies on public services delivery. Electron. Commer. Res. 2017, 17, 227-254. [CrossRef]

2. Wind, J.; Mahajan, V. Digital Marketing: The Challenge of Digital Marketing; John Wiley \& Son: New York, NY, USA, 2001.

3. Cummins, S.; Peltier, J.W.; Schibrowsky, J.A.; Nill, A. Consumer behavior in the online context. J. Res. Interact. Mark. 2014, 8, 169-202. [CrossRef]

4. Choi, Y.; Jin, J. Is the Web Marketing Mix Sustainable in China? The Mediation Effect of Dynamic Trust. Sustainability 2015, 7, 13610-13630. [CrossRef]

5. Internet World Stats. Internet Usage in Asia. Available online: http://www.internetworldstats.com/stats3. htm (accessed on 25 July 2017).

6. International Telecommunication Union Statistics. Available online: http://www.itu.int/en/ITU-D/ Statistics/Pages/stat/default.aspx (accessed on 25 July 2017).

7. Teresa, A.S.; Bonnie, D.B.; Yingjiao, X. Predicting purchase intention of a controversial luxury apparel product. J. Fash. Mark. Manag. Int. J. 2006, 10, 405-419. [CrossRef]

8. Barkhi, R.; Wallace, L. The impact of personality type on purchasing decisions in virtual stores. Inf. Technol. Manag. 2007, 8, 313-330. [CrossRef]

9. Brown, M.; Pope, N.; Voges, K. Buying or browsing? An exploration of shopping orientations and online purchase intention. Eur. J. Mark. 2003, 37, 1666-1684. [CrossRef]

10. Korgaonkar, P.; Silverblatt, R.; Becerra, E. Hispanics and Patronage Preferences for Shopping from the Internet. J. Comput. Med. Commun. 2004, 9, 31-44. [CrossRef]

11. Park, J.; Lee, D.; Ahn, J. Risk-Focused E-Commerce Adoption Model: A Cross-Country Study. J. Glob. Inf. Manag. 2014, 7, 6-30. [CrossRef]

12. Stafford, T.F.; Turan, A.; Raisinghani, M.S. International and Cross-Cultural Influences on Online Shopping Behavior. J. Glob. Inf. Manag. 2004, 7, 70-87. [CrossRef]

13. Huang, M.H. Modeling Virtual Exploratory and Shopping Dynamics: An Environmental Psychology Approach. Inf. Manag. 2003, 41, 39-47. [CrossRef]

14. Xia, L. Affect as Information: The Role of Affect in Consumer Online Behaviors. Adv. Consum. Res. 2002, 29, 93-100.

15. Bhatnagar, A.; Ghose, S. A Latent Class Segmentation Analysis of E-Shoppers. J. Bus. Res. 2004, 57, 758-767. [CrossRef]

16. Featherman, M.S.; Pavlou, P.A. Predicting E-Services Adoption: A Perceived Risk Facets Perspective. Int. J. Hum. Comput. Stud. 2003, 59, 451-474. [CrossRef]

17. Garbarino, E.; Strahilevitz, M. Gender Differences in the Perceived Risk of Buying Online and the Effects of Receiving a Site Recommendation. J. Bus. Res. 2004, 57, 768-775. [CrossRef]

18. Huang, W.Y.; Schrank, H.; Dubinsky, A.J. Effect of Brand Name on Consumers' Risk Perceptions of Online Shopping. J. Consum. Behav. 2004, 4, 40-50. [CrossRef]

19. Novak, T.P.; Hoffman, D.L.; Yung, Y.F. Measuring the Customer Experience in Online Environments: A Structural Modeling Approach. Mark. Sci. 2000, 19, 22-42. [CrossRef] 
20. Wolfinbarger, M.; Gilly, M. Shopping Online for Freedom, Control and Fun. Calif. Manag. Rev. 2001, 43, 34-56. [CrossRef]

21. Schiffman, L.G.; Kanuk, L.L. Consumer Behavior; Prentice-Hall: Upper Saddle River, NJ, USA, 2000.

22. Zhou, T.; Lu, Y. The Effects of Personality Traits on User Acceptance of Mobile Commerce. Int. J. Hum. Comput. Interact. 2011, 27, 545-561. [CrossRef]

23. Mount, M.K.; Barrick, M.R.; Scullen, S.M.; Rounds, J. Higher-Order Dimensions of the Big Five Personality Traits and the Big Six Vocational Interest Types. Pers. Psychol. 2005, 58, 447-478. [CrossRef]

24. Myung, J.K.; Choi, Y.H.; Kim, J.D. Effects of CEOs' Negative Traits on Corporate Social Responsibility. Sustainability 2017, 9, 543. [CrossRef]

25. Chin, J.; Lin, S.C. A Behavioral Model of Managerial Perspectives Regarding Technology Acceptance in Building Energy Management Systems. Sustainability 2016, 8, 641. [CrossRef]

26. Wei, X.; Jung, S. Understanding Chinese Consumers' Intention to Purchase Sustainable Fashion Products: The Moderating Role of Face-Saving Orientation. Sustainability 2017, 9, 1570. [CrossRef]

27. Greenberg, J.; Baron, R.A. Behavior in Organizations, 9th ed.; Pearson Education: Upper Saddle River, NJ, USA, 2007.

28. Huang, J.H.; Yang, Y.C. The relationship between personality traits and online shopping motivations. Soc. Behav. Personal. 2010, 38, 673-680. [CrossRef]

29. Pervin, L.A. The Science of Personality; Wiley: New York, NY, USA, 1996.

30. Hampson, S.E.; Goldberg, L.R. A first large-cohort study of personality-trait stability over the 40 years between elementary school and midlife. J. Personal. Soc. Psychol. 2006, 91, 763-779. [CrossRef] [PubMed]

31. Costa, P.T., Jr.; McCrae, R.R. Domains and Facets: Hierarchical Personality Assessment Using the Revised NEO Personality Inventory. J. Personal. Assess. 1995, 64, 21-50. [CrossRef] [PubMed]

32. Liao, Z.; Wong, W.K. The determinants of customer interactions with internet-enabled e-banking service. J. Oper. Res. Soc. 2008, 59, 1201-1210. [CrossRef]

33. Chen, Y.H.; Hsu, I.C.; Lin, C.C. Website attributes that increase consumer purchase intention: A conjoint analysis. J. Bus. Res. 2010, 63, 1007-1014. [CrossRef]

34. Liao, Z.; Shi, X.; Wong, W.K. Consumer Perceptions of the Smartcard in Retailing: An Empirical Study. J. Int. Consum. Mark. 2012, 24, 252-262. [CrossRef]

35. Liao, Z.; Shi, X.; Wong, W.K. Key determinants of sustainable smartcard payment. J. Retail. Consum. Serv. 2014, 21, 306-313. [CrossRef]

36. Moslehpour, M.; Wong, W.K.; Aulia, C.K.; Pham, V.K. Repurchase intention of Korean beauty products among Taiwanese consumers. Asia Pac. J. Mark. Logist. 2017, 29, 569-588. [CrossRef]

37. Moslehpour, M.; Wong, W.K.; Lin, Y.H.; Nguyen, T.L.H. Top purchase intention priorities of Vietnamese low cost carrier passengers: Expectations and satisfaction. Eurasian Bus. Rev. 2017, 1-19. [CrossRef]

38. Ajzen, I. The theory of planned behavior. Organ. Behav. Hum. Decis. Process. 1991, 50, 179-211. [CrossRef]

39. Pagani, M.; Goldsmith, R.E.; Hofacker, C.F. Extraversion as a stimulus for usergenerated content. J. Res. Interact. Mark. 2013, 7, 242-256. [CrossRef]

40. Mohamed, N.; Hussein, R.; Zamzuri, N.H.A.; Haghshenas, H. Insights into individual's online shopping continuance intention. Ind. Manag. Data Syst. 2014, 114, 1453-1476. [CrossRef]

41. Son, J.; Sadachar, A.; Manchiraju, S.; Fiore, A.M.; Niehm, L.S. Consumer adoption of online collaborative customer co-design. J. Res. Interact. Mark. 2012, 6, 180-197. [CrossRef]

42. Davis, F.D. Perceived usefulness, perceived ease of use, and user acceptance of information technology. MIS Q. 1989, 13, 318-340. [CrossRef]

43. Burton-Jones, A.; Hubona, G.S. Individual differences and usage behaviour: Revisiting a technology acceptance model assumption. Date Base Adv. Inf. Syst. 2005, 36, 58-77. [CrossRef]

44. Szajna, B. Empirical Evaluation of the Revised Technology Acceptance Model. Manag. Sci. 1996, 42, 85-92. [CrossRef]

45. Bruner, G.C.; Kumar, A. Explaining consumer acceptance of handheld Internet devices. J. Bus. Res. 2005, 58, 553-558. [CrossRef]

46. King, W.R.; He, J. A meta-analysis of the technology acceptance model. Inf. Manag. 2006, 43, 740-755. [CrossRef]

47. Migliore, L.A. Relation between big five personality traits and Hofstede's cultural dimensions: Samples from the USA and India. Cross Cult. Manag. Int. J. 2011, 18, 38-54. [CrossRef] 
48. Banerjee, S. Influence of consumer personality, brand personality, and corporate personality on brand preference: An empirical investigation of interaction effect. Asia Pac. J. Mark. Logist. 2016, 28, $198-216$. [CrossRef]

49. Correa, T.; Hinsley, A.W.; de Zúñiga, H.G. Who interacts on the web?: The intersection of users' personality and social media use. Comput. Hum. Behav. 2010, 26, 247-253. [CrossRef]

50. Jadin, T.; Gnambs, T.; Batinic, B. Personality traits and knowledge sharing in online communities. Comput. Hum. Behav. 2013, 29, 210-216. [CrossRef]

51. Tsao, W.C. Big Five personality traits as predictors of internet usage categories. Int. J. Manag. 2013, 30, 374-386.

52. McElroy, J.C.; Hendrickson, A.R.; Townsend, A.M.; DeMarie, S.M. Dispositional factors in Internet use: Personality versus cognitive style. MIS Q. 2007, 31, 809-820. [CrossRef]

53. Tuten, T.L.; Bosnjak, M. Understanding differences in web usage: The role of need for cognition and the Five Factor Model of personality. Soc. Behav. Personal. 2001, 29, 391-398. [CrossRef]

54. Devaraj, S.; Easley, R.F.; Crant, J.M. How Does Personality Matter? Relating the Five-Factor Model to Technology Acceptance and Use. Inf. Syst. Res. 2008, 19, 93-105. [CrossRef]

55. Punnoose, A.C. Determinants of Intention to Use e-Learning Based on the Technology Acceptance Model. J. Inf. Technol. Educ. Res. 2012, 11, 301-337.

56. Svendsen, G.B.; Johnsen, J.A.K.; Almas-Sørensen, L.; Vittersø, J. Personality and technology acceptance: The influence of personality factors on the core constructs of the Technology Acceptance Model. Behav. Inf. Technol. 2013, 32, 323-334. [CrossRef]

57. Shambare, R. Factors influencing the adoption of cell phone banking by South African students. Afr. J. Bus. Manag. 2013, 7, 30-38.

58. Rosen, P.A.; Kluemper, D.H. The Impact of the Big Five Personality Traits on the Acceptance of Social Networking Website. In Proceedings of the Fourteenth Americas Conference on Information Systems (AMCIS), Toronto, ON, Canada, 14-17 August 2008; Volume 274.

59. Kim, H.; Song, J. The quality of word-of-mouth in the online shopping mall. J. Res. Interact. Mark. 2010, 4, 376-390. [CrossRef]

60. Yoon, H.S.; Barker Steege, L.M. Development of a quantitative model of the impact of customers' personality and perceptions on Internet banking use. J. Comput. Hum. Behav. 2013, 29, 1113-1141. [CrossRef]

61. Aldás-Manzano, J.; Ruiz-Mafé, C.; Sanz-Blas, S. Exploring individual personality factors as drivers of M-shopping acceptance. Ind. Manag. Data Syst. 2009, 109, 739-757. [CrossRef]

62. Özbeka, V.; Alnıaçık, Ü.; Kocc, F.; Akkılıç, E.; Kaş, E. The Impact of Personality on Technology Acceptance: A Study on Smart Phone Users. Procedia Soc. Behav. Sci. 2014, 150, 541-551. [CrossRef]

63. Childers, T.L.; Carr, C.L.; Peck, J.; Carson, S. Hedonic and utilitarian motivations for online retail shopping behavior. J. Retail. 2001, 77, 511-535. [CrossRef]

64. Marjan, M.; Mohammad, R.E.; Ali, S.B. Influencing VSN users' purchase intentions: The roles of flow, trust and eWOM. J. Res. Interact. Mark. 2014, 8, 102-123. [CrossRef]

65. Thorbjørnsen, H.; Pedersen, P.E.; Nysveen, H. This is who I am: Identity expressiveness and the theory of planned behavior. Psychol. Mark. 2007, 24, 763-785. [CrossRef]

66. Bosnjak, M.; Galesic, M.; Tuten, T. Personality determinants of online shopping: Explaining online purchase intentions using a hierarchical approach. J. Bus. Res. 2007, 60, 597-605. [CrossRef]

67. Mowen, J.C. The 3M Model of Motivation and Personality; Kluwer Academic Press: Norwell, MA, USA, 2000.

68. Islam, J.U.; Rahman, Z.; Hollebeek, L.D. Personality factors as predictors of online consumer engagement: An empirical investigation. Mark. Intell. Plan. 2017, 35, 510-528. [CrossRef]

69. Ramayah, T.; Lo, M.C. Impact of shared beliefs on "perceived usefulness" and "ease of use" in the implementation of an enterprise resource planning system. Manag. Res. News 2007, 30, 420-431. [CrossRef]

70. Hayhoe, C.R.; Leach, L.J.; Turner, P.R.; Bruin, M.J.; Lawrence, F.C. Differences in Spending Habits and Credit Use of College Students. J. Consum. Aff. 2000, 34, 113-133. [CrossRef]

71. National Statistics Republic of China. Available online: https://eng.stat.gov.tw (accessed on 15 November 2017).

72. Blumenthal, S. Estimating population size with truncated sampling. Commun. Stat. Theory Methods 1977, 6, 297-308. [CrossRef]

73. Cochran, W.G. Sampling Techniques, 3rd ed.; Wiley: New York, NY, USA, 1977. 
74. Hair, J.F.; Black, W.C.; Babin, B.J.; Anderson, R.E. Multivariate Data Analysis; Pearson Prentice Hall: Upper Saddle River, NJ, USA, 2009.

75. Vogt, W.P.; Johnson, R.B. The SAGE Dictionary of Statistics and Methodology a Nontechnical Guide for the Social Sciences, 5th ed.; Sage Publication: London, UK, 2015.

76. Coakes, S.J.; Steed, L.; Ong, C. SPSS 16.0 for Windows: Analysis without Anguish; John Wiley and Sons: Milton, QLD, Australia, 2009.

77. Chen, J.K.C.; Batchuluun, A.; Batnasan, J. Services innovation impact to customer satisfaction and customer value enhancement in airport. Technol. Soc. 2015, 43, 219-230. [CrossRef]

78. Bentler, P.M.; Bonnet, D.G. Significance Tests and Goodness of Fit in the Analysis of Covariance Structures. Psychol. Bull. 1980, 88, 588-606. [CrossRef]

79. Bentler, P.M. Comparative Fit Indexes in Structural Models. Psychol. Bull. 1990, 107, 238-246. [CrossRef] [PubMed]

80. MacCallum, R.C.; Browne, M.W.; Sugawara, H.M. Power Analysis and Determination of Sample Size for Covariance Structure Modeling. Psychol. Methods 1996, 1, 130-149. [CrossRef]

81. Anderson, J.C.; Gerbing, D.W. Structural Equation Modeling in Practice: A Review and Recommended Two-Step Approach. Psychol. Bull. 1988, 103, 411-423. [CrossRef]

82. Fornell, C.; Larcker, D.F. Evaluating Structural Equation Models with Unobservable Variables and Measurement Error. J. Mark. Res. 1981, 18, 39-50. [CrossRef]

83. Tong, X. A cross-national investigation of an extended technology acceptance model in the online shopping context. Int. J. Retail Distrib. Manag. 2010, 38, 742-759. [CrossRef]

84. Arnold, M.J.; Reynolds, K.E. Hedonic shopping motivation. J. Retail. 2003, 79, 77-95. [CrossRef]

85. Wong, W.K.; Chow, S.C.; Hon, T.Y.; Woo, K.Y. Empirical Study on Conservative and Representative Heuristics of Hong Kong Small Investors Adopting Momentum and Contrarian Trading Strategies. Int. J. Rev. Manag. 2018, forthcoming.

(C) 2018 by the authors. Licensee MDPI, Basel, Switzerland. This article is an open access article distributed under the terms and conditions of the Creative Commons Attribution (CC BY) license (http:/ / creativecommons.org/licenses/by/4.0/). 